\title{
Usos linguísticos dos passarinheiros na região do Caeté/PA: perspectivas socioterminológicas e fraseológicas
}

\author{
Linguistic usage of the bird breeders in the region of Caeté /PA: socioterminological \\ and phraseological perspectives \\ Paulo Santiago DE SOUSA* \\ Universidade Estadual Paulista (UNESP)
}

\begin{abstract}
RESUMO: Este trabalho ocupa-se da análise de termos simples (TS) e de fraseologismos presentes nos usos linguísticos orais dos passarinheiros - sujeitos que criam, treinam e comercializam aves passeriformes - na região do Caeté/PA. Selecionamos quatro TS, dispostos em fichas terminológicas (FT) e seis fraseologismos com o termo "curió", em um quadro composto por três itens horizontais (fraseologismo, definição e contexto). O corpus advém de entrevistas realizadas com oito passarinheiros, em 2017, nos municípios de Bragança, Tracuateua e Augusto Corrêa. A base teórica selecionada centra-se, principalmente, nos postulados socioterminológicos de Faulstich (1995a; 2006) e Gaudin (1993) e em alguns estudos fraseológicos de Monteiro-Plantin (2014), Mejri (1997), Gouadec (1994), dentre outros. Esta pesquisa destaca a importância dos estudos lexicais, sobretudo a diversidade de terminologias usadas por grupos sociais existentes no território brasileiro. Os resultados indicam a existência de uma língua de especialidade utilizada pelos passarinheiros na região do Caeté/PA.
\end{abstract}

PALAVRAS-CHAVE: Região do Caeté. Passarinheiros. Termos simples. Fraseologismos.

ABSTRACT: This work deals with the analysis of simple terms (TS) and phraseologies present in the oral linguistic usage of the bird breeders - people who breed, train and sell birds - in the region of Caeté / PA. We selected four TS, arranged in terminological forms (FT) and six phraseologies with the term "curió", in a table composed of three horizontal items (phraseology, definition and context). The corpus comprises interviews with eight bird breeders, in 2017, in the cities of Bragança, Tracuateua and Augusto Correa. The theoretical basis focuses mainly on the socio-terminological postulates of Faulstich (1995a; 2006) and Gaudin (1993) and in some

\footnotetext{
* Doutorando em Linguística e Língua Portuguesa - UNESP - Araraquara - vinculado à linha de pesquisa Estudos do léxico - Bolsista CAPES/PROEX. E-mail: profpaulosantiago@gmail.com
} 
phraseological studies by Monteiro-Plantin (2014), Mejri (1997), Gouadec (1994), among others. This research highlights the importance of lexical studies, especially in the diversity of terminologies used by existing social groups in the Brazilian territory. The results indicate the existence of a specific language used by bird breeders in the region of Caeté / PA.

KEYWORDS: Caeté Region. bird breeders. Simple terms. Phraseologisms.

\section{Introdução}

Neste trabalho temos o intuito de apresentar uma amostra do léxico dos passarinheiros na região do Caeté/PA. Essa amostra contempla quatro termos simples e seis fraseologismos com o termo "curió". Para tanto, faz-se necessário situar o leitor quanto à criação de aves silvestres no Brasil, informando que este costume advém das populações indígenas, que incorporam elementos avifaunísticos em suas lendas, mitos, superstições, canções, rituais e desenhos rupestres.

Neste trabalho apresentamos uma breve análise de uma amostra do léxico dos passarinheiros na região do Caeté/PA. Essa amostra contempla quatro termos simples e seis fraseologismos com o termo "curió". Objetivamos, com este estudo, prover contribuição adicional aos estudos do campo da Terminologia e Socioterminologia com dados de uma área de especialidade pouco divulgada, bem como trazer para a reflexão acadêmica saberes e práticas populares em cuja dinâmica se incorporam termos e fraseologias específicos e em pleno uso. Para tanto, faz-se necessário situar o leitor quanto à criação de aves silvestres no Brasil, informando que este costume advém das populações indígenas, que incorporam elementos avifaunísticos em suas lendas, mitos, superstições, canções, rituais e desenhos rupestres.

Nogueira-Neto (1973) descreve que, nas aldeias brasileiras, era possível encontrar uma diversidade de espécies sendo usadas com finalidades recreativas, tais como periquitos, papagaios, araras, bem-te-vis e muitas outras espécies. É valido destacar que o aprisionamento das aves pelos indígenas não causava prejuízos à fauna, uma vez que havia consciência da preservação das espécies e harmonia entre homem e ave. Sick (1997) afirma que essa relação harmônica foi rompida com a chegada dos colonizadores, que impulsionaram o aprisionamento e a comercialização de aves de 
forma desordenada. As aves atraíam a atenção do comprador pela beleza de sua plumagem e do seu canto.

$\mathrm{Na}$ região do Caeté permanece o hábito de manter pássaros, mais especificamente os passeriformes ${ }^{1}$, em cativeiro. Constantemente veem-se nas ruas, ramais, feiras, residências, pássaros de espécies diversas em gaiolas, na maioria das vezes, sem a devida autorização de órgãos de controle ambiental ${ }^{2}$. Essas aves apresentam diferentes valores socioculturais e antropológicos dentro das comunidades locais, quer sejam por razões naturalistas ou utilitárias.

Segundo os estudos realizados por Sousa (2018, p. 17), os passarinheiros, sujeitos que criam, treinam e comercializam pássaros integram um grupo bem peculiar, que compartilham saberes e um léxico especifico. Neste trabalho elegemos para análise o léxico que se materializa em TS e fraseologismos.

Do ponto de vista da constituição lexical genérica, Barros (2004, p. 100) afirma que o termo simples é constituído por apenas um lexema. Para exemplificar, trouxemos a esse trabalho os seguintes TS: coleira, enfemear, parelha e presa. Os fraseologismos, segundo Alves (2002, apud ORTIZ, 2008) "são estruturas que integram as características de pluriverbalidade, isto é, a presença de um ou mais termos, em que um é o núcleo e as relações sintáticas e semânticas entre os componentes limitam a substituição livre dos elementos que compõem o fraseologismo."Em nível de elucidação, podemos citar: curió fogo crônico, curió preseiro, curió maracajá, curió preto, curió quente e curió trola.

Dessa forma, o corpus escolhido para análise tem igual relevância nesse trabalho por compor os usos linguísticos dos passarinheiros. Ressaltamos que os usos a que nos referimos, foram coletados por meio de entrevistas orais ${ }^{3}$.

\footnotetext{
${ }^{1}$ Passeriformes é uma ordem da classe Aves, na sua maior parte canoras, conhecidos popularmente como pássaros ou passarinhos. O grupo é bastante numeroso e diversificado, com cerca de 5.400 espécies o que representa mais da metade do total das espécies de aves. Classe gramatical: substantivo masculino plural.

2 Advertimos que este estudo tem por intento realizar unicamente um estudo no âmbito da Socioterminologia e da Fraseologia. E não se caracteriza por ser um instrumento de denúncia de ilegalidade no que tange a atividade dos passarinheiros.

${ }_{3}$ As entrevistas foram concedidas após apresentação e leitura de uma Declaração de sigilo éticocientífico, que tem por objetivo salvaguardar a integridade física e moral dos informantes.
} 


\section{Pressupostos teóricos}

\subsection{Socioterminologia - alguns fundamentos teóricos e metodológicos}

Segundo Faulstich (2006), ao dar os seus primeiros passos enquanto área de estudo, a Terminologia Clássica (TC), defendida por Eugen Wüster, indicava que o termo deveria ser uma unidade denotativa, sem relações sinonímicas, homonímicas ou polissêmicas. No entanto, a prática terminológica atual demonstra que um mesmo conceito poderá ser expresso por terminologias que apresentem variações, sejam elas morfológicas, gráficas, regionais ou socioprofissionais ${ }^{4}$. É este o princípio subjacente à socioterminologia: o registo de variantes das terminologias consoante o seu aparecimento em diferentes contextos sociais, situacionais, espaciais e linguísticos, fundamentando-se nas condições de circulação do mesmo dentro da própria linguagem. ${ }^{5}$

A socioterminologia significa uma abordagem da terminologia para o estudo do uso linguístico e visa "atenuar os efeitos prescritivos exagerados de algumas proposições normativas" (BOULANGER, 1991, p. 25).

Boulanger (1991, p. 18) defende a existência de uma evolução cronológica nos estudos terminológicos, que perpassa pela terminografia, prática mais isolada e com finalidades individuais e pessoais, pela terminologia, pela teoria estruturante e mais vinculada à institucionalização, até chegar à socioterminologia, com viés voltado para a “inserção comunitária tendo objetivos identitários".

Desde o surgimento da Socioterminologia, vários estudiosos têm dedicado a sua atividade à análise do termo nas suas variantes sociais, reconhecendo que, apesar da exigência teórica de univocidade das linguagens especializadas, não é possível excluir a existência de variações terminológicas resultantes das diferenças sociais. Na base desta acepção está a consciência de que o estabelecimento de uma terminologia própria de determinada área específica de conhecimento deve o seu sucesso a um reflexo aceite no seio da comunidade que com ela lida ou vai lidar, tornando indispensável ter em consideração a estreita relação do termo com o meio social em que é utilizado.

\footnotetext{
${ }^{4}$ As variações linguísticas consoantes os aspectos sociais surgem como um dos objetos de estudo privilegiados dentro da terminologia.

${ }^{5}$ A comunicação monolinguística dentro de um determinado grupo social e, sobretudo, a comunicação multilinguística e a troca de informações entre diferentes comunidades exercem um papel muito influente no desenvolvimento da linguagem (REY, 1995, p.7).
} 
Todavia, observamos que num mundo em que se parece dar grande importância ao "politicamente correto", a terminologia desempenha, também, um papel relevante na definição e estabelecimento de discursos quotidianos totalmente subordinados a influências políticas mais ou menos acentuadas, encontrando reflexo no discurso dos meios de comunicação e redefinindo, assim, o espectro linguístico dos falantes. Entre os objetivos teóricos deste cuidado linguístico encontram-se, entre outros, um aumento da qualidade linguística na comunicação, um melhoramento da relação entre os falantes e a língua, a redução das distinções sociais entre os falantes e, talvez mais obscuramente, a imposição de uma determinada visão da sociedade através das próprias regras linguísticas. Questões desta natureza excedem a terminologia, em si, e os seus objetivos primeiros, sendo, na realidade, ponto de partida para uma análise mais específica na socioterminologia.

É perceptível que, a cada dia, a socioterminologia adquire bases teóricas e metodologias próprias que a distinguem dentro da Terminologia. No seu estatuto de trabalho prático, ela baseia-se na análise das condições de funcionamento dos termos enquanto elementos de comunicação e interação dentro de todo um sistema linguístico e social. Para tal, ela adquiriu, não só os princípios da sociolinguística, como sejam os critérios de variação linguística e as perspectivas de mudança, como também os princípios etnográficos de interação e comunicação social.

Logo, depreendemos que a abordagem socioterminológica consiste em um novo enfoque terminológico, contemplando instrumentos teóricos e metodológicos no intuito de "introducir la terminología en la práctica social que es todo discurso, incluído el discurso metatermilógico con el objetivo de examinarlo como actividade produtora / social y como actividade cognosctiva"” (BORBUJO, 2001, p. 661).

Para Gaudin (1993 , p. 221), a socioterminologia enquanto atividade cognitiva prevê que a unidade terminológica ${ }^{7}$, inserida no sistema de língua de especialidade, reflete uma representação, uma maneira de ver as coisas, o mundo. Enquanto atividade social, a socioterminologia induz que a unidade terminológica consiste numa "outil de travail et de production de sens dans une sphère d'activité", (GAUDIN, 1993ª , p. 221).

\footnotetext{
6 “introduzir a terminologia na prática social que é todo discurso, incluindo o discurso metatermológico com o objetivo de examiná-lo como atividade produtiva / social e como atividade cognoscitiva".

${ }^{7}$ Denominação usada por Gaudin $\left(1993^{a}\right.$, p. 221) e Borbujo (2001, p. 662) como sinônimo de termo.

8 "uma ferramenta para trabalhar e produzir significado em uma esfera de atividade".
} 
Consequentemente, é no seio do discurso, e aqui entendemo-lo "no lo sequencia de palabras / de términos, receptáculo de informaciones, datos y conceptos, sino como lugar de fuerzas, de negociación de sentido, de equilíbrio entre necessidades y formas de denominacíon, como lugar y forma producidos por lagunas posiciones sócioideológicas" "9 (BORBUJO, 2001, p. 662). A palavra adquire, desse modo, o estatuto de unidade terminológica reconhecida, resultando de uma construção e de uma apropriação do mundo real por parte do falante.

A socioterminologia adquiriu fundamentos teóricos e metodológicos que são próprios de uma disciplina e não somente de um método de pesquisa, com duas sólidas abordagens: a prática do trabalho terminológico, que considera as situações de circulação dos termos no movimento cotidiano da linguagem; e como uma disciplina prescritiva, em que estes são estudados sob a ótica da interação social. (FAULSTICH, 1995).

Na concepção de Faulstich $\left(1995^{\mathrm{a}}\right)$, a Socioterminologia se configura por ser:

[...] a disciplina que se ocupa da identificação e da categorização das variantes linguísticas dos termos em diferentes tipos de situação de uso da língua. Para que o linguista, especialista em terminologia, desenvolva seu trabalho de pesquisa, é preciso levar em conta critérios básicos de variação terminológica no meio social, bem como critérios etnográficos, porque as comunicações entre membros da comunidade em estudo podem gerar termos diferentes para um mesmo conceito ou mais de um conceito para o mesmo termo. (1995a, p. 1).

A autora defende que a teoria da variação terminológica tem por meta considerar os diferentes valores que o termo pode assumir, conforme a função e o contexto em que ele se encontra. Assim, seu estatuto fica assegurado pela análise da diversidade de terminologias que ocorrem nos planos vertical, horizontal e temporal da língua.

Ao reconhecer a variação em terminologia, Faulstich (1995a) estabelece como postura para a validação do trabalho socioterminológico: identificar o falante da terminologia a ser descrita; adotar atitude descritiva; consultar especialista na área;

\footnotetext{
9 “não o sequenciamento de palavras / termos, receptáculo de informação, dados e conceitos, mas sim como um lugar de forças, de negociação de significado, de equilíbrio entre necessidades e formas de denominação, como lugar e forma produzidos por certas posições sócio-ideológicas".
} 
delimitar o corpus; selecionar aporte bibliográfico pertinente; precisar as condições de produção e de recepção do texto de especialidade; outorgar, na análise do funcionamento dos termos, estatuto principal à sintaxe e à semântica; registrar o termo e sua(s) variante (es) e, por fim, escrever repertórios terminológicos.

Em síntese, o que se pretende, em Socioterminologia, é considerar os diversificados discursos especializados, incluindo os contextos orais e aceitando as variações terminológicas e que tais variações devem estar presentes de forma adequada e satisfatória na elaboração dos produtos terminográficos.

\subsection{Fraseologia - breve incursão}

Fraseologia é o nome utilizado "para designar tanto o conjunto de fenômenos fraseológicos como a disciplina que os estuda" (MONTEIRO-PLANTIN, 2014, p. 21). Contudo, no Brasil, tem-se preferido, para designar o objeto de estudo, o uso de "unidade fraseológica" e "fraseologismo", já "Fraseologia" faria referência à disciplina científica. Desse modo, os fraseologismos apresentam características distintas das unidades lexicais simples:

\footnotetext{
Com essa noção de que uma unidade fraseológica é um arquilexema da série de denominações fraseológicas, podemos apresentar as propriedades essenciais e definitórias das chamadas unidades fraseológicas: polilexicalidade, frequência, convencionalidade, fixação e idiomaticidade (MARTINS, 2013, p. 32).
}

A definição acima trata de aspectos gerais que, de certa forma, estão presentes nas múltiplas estruturas estudadas pela Fraseologia, mas, além de possuírem certas características comuns, também apresentam traços pragmáticos, semânticos ou sintáticos que as distinguem umas das outras, o que pode ter influenciado a variedade de denominações.

Bevilacqua (1995, p. 846) postula que a fraseologia de língua comum apresenta as características de "impossibilidade de alteração da ordem de seus componentes, de inserção de outros componentes e de substituição de determinado componente ou de 
determinada categoria gramatical", embora sejam permitidas alterações de tempo verbal.

Conforme a mesma autora, pode-se entender a "fraseologia tanto de Língua Comum e de Especialidade como a combinação de elementos linguísticos de uma dada língua, relacionados semântica e sintaticamente, que não pertencem a uma categoria gramatical específica e cujo significado é dado pelo conjunto de seus elementos" (1995, p. 846).

Adotamos para este trabalho a denominação fraseologismo para nos referir ao fenômeno da linguagem que se exprime através de associações sintagmáticas recorrentes em determinados discursos (MEJRI, 1997). Parte-se do princípio de que as unidades fraseológicas são combinações de unidades léxicas, relativamente estáveis, formadas por duas ou mais palavras, que constituem a competência discursiva dos falantes, utilizadas convencionalmente em contextos precisos, com objetivos específicos, a exemplo dos fraseologismos com o termo "curió", usados pelos passarinheiros.

Buscamos também em Gouadec (1994) orientações para analisarmos os fraseologismos com o termo "curió". Para Gouadec há duas categorias de Unidades Fraseológicas, as com pivô terminológico e as sem pivô terminológico. Nossa análise encontra reverberação teórica e metodológica na concepção de Unidade Fraseológica com pivô terminológico, uma vez que o núcleo fixo é "curió", admitindo variáveis a esse núcleo.

\section{Metodologia da pesquisa}

\section{1 Área do estudo}

Segundo dados do IBGE, o estado do Pará é composto por 143 municípios, distribuídos em 12 regiões de integração. A Região de Integração (RI) Caeté é composta por 15 municípios (Augusto Corrêa, Bonito, Bragança, Cachoeira do Piriá, Capanema, Nova Timboteua, Peixe-Boi, Primavera, Quatipuru, Salinópolis, Santa Luzia do Pará, Santarém Novo, São João de Pirabas, Tracuateua e Viseu). A formação de seu território é oriunda da aglutinação de municípios das microrregiões Bragantina e Salgado. Algumas cidades e municípios foram criados em períodos anteriores à construção da 
Estrada de Ferro Belém-Bragança, que teve início em 1883 e término em 1906, entretanto, foi durante a construção da ferrovia que ocorreu a intensificação do processo de ocupação e colonização dessa região. O mapa abaixo mostra o estado do Pará, dividido por RI. Em destaque está a Região do Caeté ou Rio Caeté.

Mapa 1: Regiões de Integração do Pará

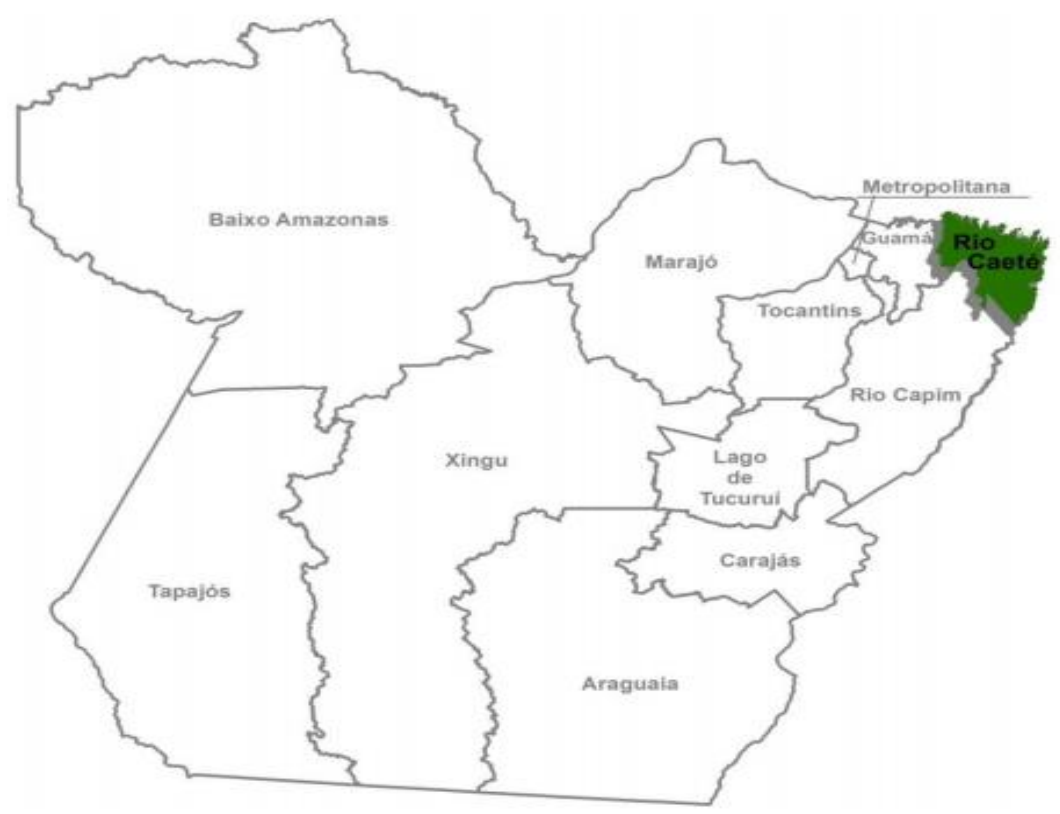

Fonte: COSTA \& PIRES $(2016)^{10}$

Localizada no Nordeste do Pará, a região é entrecortada pelas rodovias BR-316 e BR-308. Abrange uma área de quase 17 mil quilômetros quadrados, o que representam $1,5 \%$ da área total do Pará.

A população da região do Caeté, em 2014, foi estimada em 494 mil habitantes, correspondendo a $6 \%$ do total do Estado. Bragança é o município com o maior contingente de pessoas, com 120 mil (24\%), seguido por Capanema com 66 mil (13\%) e Viseu 59 mil (12\%), juntos concentram 49\% da população da região (245 mil habitantes). A taxa de crescimento populacional, entre 2010 e 2014, foi de 5,35\%, abaixo da média estadual $(6,91 \%)$.

\footnotetext{
${ }^{10}$ Diagnóstico Socioeconômico e Ambiental da Região de Integração Rio Caeté.

Disponível em: http://www.seplan.pa.gov.br/ppasite/perfisregionais/Perfil_Regiao_Rio_Caete.pdf. Acesso em 07 de jan. de 2020.
} 
Conforme Oliveira (2008), a região recebeu esse nome em decorrência dos índios caetés que habitaram essa região por longos anos ${ }^{11}$. Por consequência, o rio que banha a cidade de Bragança recebeu o nome de rio caeté, no singular, nome popularmente mais divulgado que rio caetés, recorrente em alguns sites que tratam da distribuição das RI do Pará. Adotamos, neste trabalho, o nome região do caeté, considerando o topônimo mais usual para os moradores.

Esta pesquisa centrou-se em três municípios: Tracuateua, Augusto Corrêa e Bragança, pela proximidade das cidades e, consequentemente, por oferecer melhor acesso ao pesquisador.

\subsection{Método de investigação para levantamento dos dados}

Utilizamos, neste trabalho, como método para levantamento de dados, a observação e a entrevista oral. Para Lakatos e Marconi (2003), a observação é uma técnica de coleta de dados para conseguir informações e utiliza os sentidos na obtenção de determinados aspectos da realidade. Esse método não consiste apenas em ver e ouvir, mas também em examinar fatos que se deseja estudar. A observação ajuda o pesquisador a identificar e a obter provas a respeito de objetivos sobre os quais os indivíduos não têm consciência, mas que orientam seu comportamento. Está mais diretamente ligada à pesquisa de campo.

A entrevista, por sua vez, é uma das técnicas de coleta de dados mais usada no âmbito das ciências humanas. Ribeiro (2008, p. 141) afirma que a entrevista é fundamental "quando o pesquisador quer obter informações a respeito do seu objeto, que permitam conhecer sobre atitudes, sentimentos e valores subjacentes ao comportamento", o que significa que se pode ir além das descrições das ações, incorporando novas fontes para a interpretação dos resultados pelos próprios entrevistadores.

\footnotetext{
${ }^{11}$ Encontramos o primeiro registro sobre a região do Caeté datado de 08 de julho de 1613, período da expulsão dos franceses do Estado do Maranhão - terra até então habitada por índios tupinambá. Comandados por Daniel de La Touche, Senhor de La Revardière: "Os franceses dessa expedição, sendo avisados pelos silvícolas foram conduzidos por estes, em igarapés, atravessando o rio Caeté para a tabamaloca". (PEREIRA, 1967, p. 43). Outro registro sobre a região data da fundação do forte do Presépio no ano de 1616, quando o alferes Pedro Teixeira foi incumbido de abrir um caminho terrestre da vila de Belém do Grão- Pará para a vila de São Luís, para levar a notícia da fundação da vila do Pará. O alfere descreve o empreendimento, relatando que ao passar pelo rio Caeté, enfrentou índios ferozes e os reduziu à obediência. (PEREIRA, 1967, p. 47).
} 
Na pesquisa usamos dois tipos de entrevistas: a estruturada ou formalizada e a não estruturada ou despadronizada. A estruturada ou formalizada é aquela em que o entrevistador segue um roteiro previamente estabelecido. Ela se desenvolve a partir de uma relação de perguntas, cuja ordem e redação permanecem praticamente invariáveis para todos os entrevistados. Na entrevista não estruturada ou despadronizada o entrevistador tem liberdade para desenvolver cada situação em qualquer direção que considere adequada. (GIL, 1999).

Os tipos de pesquisa adotados neste trabalho ancoram-se no modelo de questionário sublinhado do tipo semiaberto ou semiestruturado, que consiste em um roteiro para entrevista, com questões que podem variar, dependendo da análise que se pretende realizar. O entrevistador e o entrevistado têm liberdade para fazer e responder às questões, respectivamente. (ROSA; ARNOLDI, 2006).

\subsection{Recursos para coleta, organização das fichas terminológicas e análise dos dados}

Foram utilizados para gravar as entrevistas, equipamentos tecnológicos audiovisuais, que mostram detalhes da explicação do informante, como as técnicas de manuseio dos passeriformes, treinamentos específicos que melhoram o desempenho do pássaro quanto ao seu canto, ousadia e bravura, bem como as peculiaridades que caracterizam o cotidiano de um passarinheiro ou daquele que somente prende pássaro. Nesse contexto, o entrevistador teve a função de aplicar o questionário semiestruturado, incentivando o informante a falar sobre o assunto pesquisado, sem, entretanto, forçá-lo a responder, objetivando alcançar os objetivos do trabalho.

Os dados inquiridos na pesquisa de campo foram transcritos de maneira grafemática, segundo Kock (1997), com o auxílio do programa Listen N Write ${ }^{12}$. Utilizamos, também, o programa AntConc 3.4.4 ${ }^{13}$, que é um software de uso livre desenvolvido por Laurence Anthony, PhD em Linguística Aplicada pela Universidade de Birmingham, Inglaterra, e, atualmente, docente na Faculty of Science and Engineering da Universidade de Waseda, no Japão. Esse programa foi de enorme

\footnotetext{
${ }^{12} \mathrm{O}$ programa é constituído basicamente de duas janelas. Uma janela mostra o arquivo de áudio em execução, com informações sobre a gravação, botões para avançar, pausar e retroceder etc. e a outra é um pequeno editor de textos para o usuário digitar a conversa que está ouvindo.

${ }^{13}$ Disponível em http://www.laurenceanthony.net/software.html
} 
relevância para organizar a lista de termos em ordem alfabética, bem como para a recorrência destes no corpus.

O período de organização das fichas terminológicas ocorreu posteriormente ao levantamento dos dados. Iniciamos a organização das fichas terminológicas em maio de 2017 e concluímos em fevereiro de 2018. A seguir, apresentamos um quadro dos 04 termos simples elencados para esta análise, bem como a ocorrência deles na fala dos colaboradores da pesquisa.

Quadro 1: Lista de termos simples

\begin{tabular}{|c|c|l|}
\hline $\mathrm{N}^{\circ}$ & TS & \multicolumn{1}{c|}{ OCORRÊNCIA } \\
\hline 01 & Coleira & CPI, CPII, CPIII, CPIV, CPV, CPVI, CPVII, CPVIII \\
\hline 02 & Enfemear & CPII, CPIII, CPIV, CPV, CPVI, CPVII \\
\hline 03 & Parelha & CPI, CPII, CPIII, CPIV, CPV, CPVI, CPVIII \\
\hline 04 & Presa & CPI, CPII, CPIII, CPV, CPVI, CPVII, CPVIII \\
\hline
\end{tabular}

Fonte: Dados organizados pelos autores.

\section{4 critérios para organização da ficha terminológica}

Para proceder à análise socioterminológica dos termos, estruturamo-los em fichas terminológicas que, segundo Faulstich (1996), facilitam a visualização dos aspectos que compõem a estrutura lexical dos elementos constitutivos das lexias coletadas. Além das orientações propostas por Faulstich, baseamo-nos nas proposições de Boutin-Quesnel (1985, p. 28 apud BARROS, 2004, p. 2011), que orienta o terminológo a organizar a ficha terminológica de acordo com a natureza da pesquisa, contendo os campos predeterminados a registrar as informações que atendam as particularidades do estudo em questão. Isso se faz importante para melhor compreendermos as nomeações e as significações descritas pelos passarinheiros nesse processo de nomeação, relacionado ao conhecimento e aos saberes dos CP. O quadro a seguir apresenta os componentes da ficha terminológica. 
Quadro 2: Componentes da ficha terminológica

\begin{tabular}{|c|c|}
\hline Abreviatura & Nome \\
\hline $\mathbf{L x}$ & Lexema \\
\hline Det & Data de coleta do termo \\
\hline Icp & Idioma do colaborador da pesquisa \\
\hline $\mathbf{V a}$ & Variante $^{14}$ \\
\hline $\mathrm{Cg}$ & Classe Gramatical \\
\hline Co & Contexto \\
\hline Df & Definição \\
\hline Fc & Fonte do Contexto \\
\hline Ftc & Frequência do termo no corpus \\
\hline Def & Data de elaboração da ficha \\
\hline $\mathbf{N t}$ & Nota \\
\hline
\end{tabular}

Fonte: Dados organizados pelos autores.

\section{Socioterminologia dos passarinheiros - termos simples}

O objetivo, aqui, é propor uma análise socioterminológica do léxico usado pelos passarinheiros na região do Caeté, estado do Pará. Esse léxico foi inquirido na pesquisa de campo, visando constituir um corpora que apresente a terminologia no seu contexto de uso. As exemplificações postas nas fichas terminológicas fazem parte do cotidiano linguageiro de todos os $\mathrm{CP}$.

\section{Termo 01 - Coleira}

Quadro 3 - Ficha terminológica do termo Coleira

\begin{tabular}{|l|c|l|}
\hline Lx & Lexema & Coleira \\
\hline Dct & Data de coleta & O2 de setembro de 2017 \\
\hline Icp & $\begin{array}{c}\text { Idioma do colaborador } \\
\text { da pesquisa }\end{array}$ & $(x)$ Português ( ) Espanhol ( ) Inglês ( ) Outra Língua \\
& Variante & $\varnothing$ \\
\hline Va & & \\
\hline
\end{tabular}

\footnotetext{
${ }^{14}$ Utilizamos o símbolo “ $\varnothing ”$ para os termos com ausência de variante.
} 


\begin{tabular}{|c|c|c|}
\hline $\mathrm{Cg}$ & Classe gramatical & Substantivo feminino \\
\hline Co & Contexto & $\begin{array}{l}\text {... a coleira tem muito ( ) tem em quase todo lugar, principalmente } \\
\text { onde tem muito capim ... eu tenho uma coleira muito boa de briga e } \\
\text { cantadeira ... ela não se cala para outra não ... não esfria mesmo ... } \\
\text { eu já enjeitei quatrocentos reais nela ... é muito mansa ... já vive } \\
\text { presa há mais de três anos. }\end{array}$ \\
\hline Df & Definição & $\begin{array}{l}\text { Ave passeriforme da família Thraupidae, cujo nome científico é } \\
\text { Sporophila caerulescens. (SICK, 1997). }\end{array}$ \\
\hline Fc & Fonte do contexto & O Colaborador da Pesquisa \\
\hline Ftc & $\begin{array}{l}\text { Frequência do termo no } \\
\text { corpus }\end{array}$ & 17 \\
\hline Dcf & $\begin{array}{l}\text { Data de criação da } \\
\text { ficha }\end{array}$ & 10 de setembro de 2017. \\
\hline $\mathbf{N t}$ & Nota & $\begin{array}{l}\text { O nome tem relação com as características físicas, especialmente } \\
\text { com as cores da plumagem deste passeriforme. }\end{array}$ \\
\hline
\end{tabular}

Fonte: Dados catalogados durante a pesquisa, 2017.

\section{Termo 02 - Enfemear}

Quadro 4 - Ficha terminológica do termo Enfemear

\begin{tabular}{|c|c|c|}
\hline $\mathbf{L x}$ & Lexema & Enfemear \\
\hline Dct & Data de coleta & 19 de outubro de 2017 \\
\hline Resp. & Responsável & Paulo Santiago de Sousa \\
\hline Icp & $\begin{array}{l}\text { Idioma do colaborador } \\
\text { da pesquisa }\end{array}$ & (x) Português ( ) Espanhol ( ) Inglês ( ) Outra Língua \\
\hline $\mathbf{V a}$ & Variante & $\varnothing$ \\
\hline $\mathrm{Cg}$ & Classe gramatical & Verbo - forma nominal infinito $\left(1^{a}\right.$ conjugação) \\
\hline Co & Contexto & $\begin{array}{l}\text {... é o período da chuva ... o inverno ... é:.: os meses de janeiro até } \\
\text { junho, julho... nesses meses é melhor para a gente enfemear os } \\
\text { passarinhos ... tem passarinho que fica muito dependente da fêmea } \\
\text { para cantar ... é..... canta mais na presença da fêmea ... então } \\
\text {...como as fêmeas estão mais ((risos)) é.:. digo ... elas estão a } \\
\text { procura de um parceiro, fica bom para enfemear o nosso } \\
\text { passarinho ... }\end{array}$ \\
\hline Df & Definição & $\begin{array}{l}\text { Ato de se colocar o passarinho da gaiola próximo a uma fêmea } \\
\text { para ele cantar mais. }\end{array}$ \\
\hline Fc & Fonte do contexto & O Colaborador da Pesquisa \\
\hline
\end{tabular}




\begin{tabular}{|l|c|l|}
\hline Ftc & $\begin{array}{c}\text { Frequência do termo no } \\
\text { corpus }\end{array}$ & 12 \\
\hline Dcf & $\begin{array}{c}\text { Data de criação da } \\
\text { ficha }\end{array}$ & 29 de outubro de 2017 \\
\hline $\mathbf{N t}$ & Nota & $\begin{array}{l}\text { Pássaro "enfemeado" é aquele que fica dependente de uma fêmea } \\
\text { para cantar. }\end{array}$ \\
\hline
\end{tabular}

Fonte: Dados catalogados durante a pesquisa, 2017.

\section{Termo 03 - Parelha}

Quadro 5 - Ficha terminológica do termo Parelha

\begin{tabular}{|c|c|c|}
\hline $\mathbf{L x}$ & Lexema & Parelha \\
\hline Det & Data de coleta & 02 de agosto de 2017 \\
\hline Resp. & Responsável & Paulo Santiago de Sousa \\
\hline Icp & $\begin{array}{l}\text { Idioma do colaborador } \\
\text { da pesquisa }\end{array}$ & (x) Português ( ) Espanhol ( ) Inglês ( ) Outra Língua \\
\hline $\mathbf{V a}$ & Variante & $\varnothing$ \\
\hline $\mathrm{Cg}$ & Classe gramatical & Substantivo feminino \\
\hline Co & Contexto & $\begin{array}{l}\text {... eu sempre gosto de colocar o meu curió de parelha, pelo menos } \\
\text { eu vejo o potencial DELE ((risos)) ... a parelha é bem legal ( ) eu } \\
\text { mesmo acho animado ... é BOM porque a parelha não precisa ser } \\
\text { só no mato ... pode até ser na rua ... é na rua mesmo ... assim ... } \\
\text { perto de mato ... de capinzal ... não precisa a gente ir pra longe ...as } \\
\text { vezes tem um monte de gaiola para a gente fazer parelha ... aí fica } \\
\text { mais animado ((risos })) \text {... }\end{array}$ \\
\hline Df & Definição & $\begin{array}{l}\text { Ato de se colocar dois pássaros próximos para cantar e disputar o } \\
\text { canto. }\end{array}$ \\
\hline Fc & Fonte do Contexto & O Colaborador da Pesquisa \\
\hline Ftc & $\begin{array}{l}\text { Frequência do termo no } \\
\text { corpus }\end{array}$ & 09 \\
\hline Def & $\begin{array}{l}\text { Data de criação da } \\
\text { ficha }\end{array}$ & 20 de agosto de 2017. \\
\hline $\mathbf{N t}$ & Nota & É sinônimo de par. (CUNHA, 1986) \\
\hline
\end{tabular}

Fonte: Dados catalogados durante a pesquisa, 2017.

\section{Termo 4 - PRESA}


Quadro 6 - Ficha terminológica do termo Presa

\begin{tabular}{|c|c|c|}
\hline $\mathbf{L x}$ & Lexema & Presa \\
\hline Det & Data de coleta & 16 de junho de 2017 \\
\hline Resp. & Responsável & Paulo Santiago de Sousa \\
\hline Icp & $\begin{array}{l}\text { Idioma do colaborador } \\
\text { da pesquisa }\end{array}$ & (x) Português ( ) Espanhol ( ) Inglês ( ) Outra Língua \\
\hline $\mathbf{V a}$ & Variante & $\varnothing$ \\
\hline $\mathrm{Cg}$ & Classe gramatical & Substantivo feminino \\
\hline Co & Contexto & $\begin{array}{l}\text {... um momento importante da passarinhada é quando tamos no } \\
\text { mato e acontece a presa ( ) isso é o sinal que o nosso pássaro está } \\
\text { bem treinado e pronto para o mato ... o curió principalmente ... } \\
\text { porque ( ) é o passarinho que mais levamos para o mato e é aquele } \\
\text { também que dá ... dá mais dinheiro e diversão ... na hora da presa } \\
\text { é uma alegria só ... }\end{array}$ \\
\hline Df & Definição & $\begin{array}{l}\text { Ato em que um passeriforme prende com as garras e bico outro } \\
\text { pássaro da mesma espécie. }\end{array}$ \\
\hline Fc & Fonte do contexto & O Colaborador da Pesquisa \\
\hline Ftc & $\begin{array}{l}\text { Frequência do termo no } \\
\text { corpus }\end{array}$ & 12 \\
\hline Def & $\begin{array}{l}\text { Data de criação da } \\
\text { ficha }\end{array}$ & 27 de outubro de 2017. \\
\hline $\mathbf{N t}$ & Nota & É o ápice da disputa entre os pássaros. \\
\hline
\end{tabular}

Fonte: Dados catalogados durante a pesquisa, 2017.

3.1 Análise socioterminológica dos termos simples

Neste tópico faremos uma análise dos termos simples elencados para este trabalho. Ratificamos que TS se caracteriza por apresentar apenas um radical (ISO 1087, 1990, p. 7). Com fins metodológicos, priorizamos por topicalizar o primeiro paragrafo concernente à análise socioterminológica de todos os termos, conforme o que se segue.

- A relação do termo coleira com seu aspecto físico - colar branco e negro ao lado da garganta - lembra o que argumenta Biderman em seu artigo "Dimensões da palavra", "É a partir da palavra que as entidades da realidade podem ser nomeadas e identificadas." E explica, ainda, que a atividade de nomear as coisas é específica dos seres humanos, determinada, na sua grande maioria, em resposta aos estímulos 
observados no meio ambiente, ou seja, "supõe também a capacidade de discriminação de traços distintivos entre os referentes percebidos ou apreendidos pelo aparato sensitivo e cognitivo do indivíduo" (BIDERMAN, 1998, p. 88). Nesse caso, a representação fônica do nome coleira não é uma atividade linguística meramente arbitrária; a palavra tem relação direta com o ser, a ave.

Do ponto de vista socioterminológico o termo coleira ganha um conceito peculiar nos usos linguísticos dos passarinheiros. E não se pensa em outra coisa que não seja esse passeriforme canoro. No âmbito do léxico geral coleira pode ser um acessório para animal, por exemplo, coleira para cachorro. Mas em um grupo de pessoas que compartilham de uma terminologia própria, a exemplo dos passarinheiros, o uso do lexema coleira está relacionado a uma ave. Por isso que a socioterminologia proposta por Gaudin (1993) nos orienta a privilegiar o meio em que o termo foi mencionado, a área de domínio de que ele faz parte, a fim de se conhecer e compreender o conceito atribuído ao termo dentro de um campo de especialidade.

- O segundo termo simples exposto em ficha terminológica é enfemear, e tem o seguinte significado: prática de se colocar o passarinho da gaiola próximo a uma fêmea para ele cantar mais. Geralmente essa fêmea é nativa, ou seja, vive na natureza, não está na gaiola e é melhor para se realizar o treinamento, porque ela sobrevoa a gaiola, tem mais atitude, é mais insinuante, pelo fato de estar livre no seu habitat.

Os passarinheiros dizem que, após o treinamento com as fêmeas, o passarinho macho fica quente e por, pelo menos, três dias fica mais valente e cantador. Isso dá prestígio ao pássaro, aumenta as chances de vendas e trocas e deixa o passarinheiro contente ao ponto de não querer muitas vezes desfazer-se do passarinho, pelo fato de vê-lo cantando, em estado de júbilo.

Pela característica definicional do verbo enfemear presente no léxico dos passarinheiros, fez-se necessário mais detalhes socioterminológicos desse termo. À luz dos postulados de Faustich $(1995 ; 2001 ; 2006)$ e Cabré $(1993 ; 1999)$, criamos uma ficha terminológica própria, com os campos preenchidos, exceto o campo variante. Concluímos, portanto, que o termo enfemear integra o repertório terminológico dos passarinheiros, pois denota uma realidade linguística da atividade dos passarinheiros. Enfemear nos remete a pensar em fêmea e, de fato, há uma relação entre o verbo e o substantivo feminino, já que enfemear o pássaro é aproximá-lo sempre de uma fêmea, 
uma vez que muitos deles desenvolvem naturalmente ou via treinamento à dependência de uma fêmea para cantar.

- O termo parelha, por sua vez, foi mencionado por sete $\mathrm{CP}^{15}$. Isso nos leva a acreditar que este termo encontra-se em constante uso, assumindo, de fato, sua função comunicativa dentro do grupo de indivíduos que o elencou para fazer parte seu acervo linguístico. Observando seu contexto de circulação, a atividade dos passarinheiros, parelha é a ação de colocar dois pássaros bem próximos um do outro para disputar o canto. Nem sempre um pássaro vence a disputa, principalmente quando ambos estão bem treinados, o que prolonga o tempo do embate. Os passarinheiros dizem que colocar os pássaros em parelha, (par), ajuda a melhorar o desempenho da cantoria, pois a disputa é uma forma de acirrar a valentia e a defesa do território, mesmo que os pássaros estejam em gaiolas.

Para as pessoas que não fazem parte da atividade dos passarinheiros, o substantivo parelha não alcança sua abrangência semântica, conforme estamos traduzindo, podendo, mesmo, não ser compreendido. No entanto, sua importância é valiosa. E, por isso, frequentemente usada pelos passarinheiros. Eles têm a real dimensão semântica e pragmática dessa terminologia, usando-a de forma adequada e coerente nos seus contextos discursivos, daí a justificativa de analisá-la pela ótica socioterminológica (FAULSTICH, 1990).

- Quanto ao termo presa, recorrente na fala dos passarinheiros, recordamos que o estudo do léxico nos permite depreender uma série de conceitos e valores indenitários e culturais pela análise de determinados itens lexicais. Segundo Duranti (2000), o item lexical é capaz de modelar a cultura e revelar muitos enigmas de um grupo de pessoas. A relação entre língua e cultura é essencial para entendermos que é por meio do léxico comum ou específico que o homem expressa suas profissões, costumes, medos, angústias, sonhos, tristezas, etc.

O significado de presa indica o momento exato em que o passarinho da gaiola usa de suas habilidades para aprisionar com suas garras e bicos o outro pássaro. Esse momento é festejado e indica o estágio de valentia e desenvoltura que aquele passeriforme alcançou. Os passarinheiros passam anos treinando o pássaro para o momento da presa e, quando acontece, há um clima de celebração, pois é o cume da

\footnotetext{
${ }^{15}$ Ver quadro 02, termo número 04.
} 
maturidade do pássaro; ele está pronto para qualquer desafio que envolva briga com pássaro nativo.

No plano das categorias gramaticais, presa pertence à classe dos substantivos, sendo a classe que alça com mais recorrência a condição de termo (KRIEGER \& FINATTO, 2004). Isso acontece, porque os termos tem o atributo de nomear objetos, conceitos e ideias, confundindo-se com a própria definição de substantivo. No entanto, o fato de, em grande parte, serem representados por substantivo é mais uma constatação do que um parâmetro prescritivo.

\subsection{Fraseogismos dos passarinheiros}

A finalidade deste tópico é apresentar 06 fraseologismos com o termo "curió"16, suas respectivas definições e contextos de uso, corroborando com as pesquisas da diversidade linguística do português falado no Brasil. Para tanto, organizamo-los dentro de um quadro em ordem alfabética e destacamo-los em negrito.

\section{Quadro 8 - Fraseogismos}

\begin{tabular}{|c|c|c|}
\hline FRASEOLOGISMO & DEFINIÇÃO & CONTEXTO \\
\hline Curió fogo crônico & $\begin{array}{l}\text { capacidade perene que o pássaro tem de } \\
\text { disputar no canto e na briga em presença } \\
\text { de outro macho. }\end{array}$ & $\begin{array}{l}\text {... ele tem que ser bem manso } \\
\text { MESMO ... agora o fogo crônico é o } \\
\text { melhor ... ele não esfria ... canta } \\
\text { muito e é sempre bom de briga ... } \\
\text { (CPI) }\end{array}$ \\
\hline Curió preseiro & $\begin{array}{l}\text { habilidade de segurar/prender o curió } \\
\text { nativo, usando o bico e as garras. }\end{array}$ & $\begin{array}{l}\text {... o curió preseiro é admirado e } \\
\text { cobiçado ... é CARO um curió } \\
\text { preseiro, não é qualquer um que pode } \\
\text { comprar não ... (CPIII) }\end{array}$ \\
\hline Curió maracajá & $\begin{array}{l}\text { período em que a plumagem do curió } \\
\text { tem pigmentos pretos e castanhos. }\end{array}$ & $\begin{array}{l}\text {... quando tenho um curió maracajá } \\
\text {... começo aos poucos levando ele } \\
\text { para o mato () para ele ir } \\
\text { acostumando, mas não pode ser } \\
\text { muito forçado porque o curió }\end{array}$ \\
\hline
\end{tabular}

\footnotetext{
${ }^{16}$ No corpus encontramos com o auxilio do programa Ant Conc 18 fraseologismos com o termo "curió". Optamos por colocar neste trabalho os fraseologismos mais recorrentes.
} 


\begin{tabular}{|c|c|c|}
\hline & & $\begin{array}{l}\text { maracajá ainda é jovem, não aguenta } \\
\text { muita disputa ... o curió maracajá } \\
\text { tem as penas pintadas, assim ... com } \\
\text { várias cores ... pintas pretas, marrom } \\
\text { e... cor ... acho que castanho .... (CP } \\
\text { VIII) }\end{array}$ \\
\hline Curió preto & $\begin{array}{l}\text { plumagem superior do seu corpo é preta, } \\
\text { a parte inferior é castanho-avermelhado } \\
\text { e a parte interna das asas é branca. }\end{array}$ & $\begin{array}{l}\text {... o curió preto é mais forte para } \\
\text { cantá e brigá ... ele já tá velho ... e } \\
\text { tem mais o ... o curió preto é muito } \\
\text { bonito ... (CPII) }\end{array}$ \\
\hline Curió quente & $\begin{array}{l}\text { período em que o curió está cantando } \\
\text { muito e disposto a briga e ao canto. }\end{array}$ & $\begin{array}{l}\text {... curió quente é outra coisa ... ele } \\
\text { fica assim quando a gente volta do } \\
\text { mato ... canta, canta e quer brigar ... } \\
\text { o curió quente parece que fica } \\
\text { impaciente ... pulo de um lado para o } \\
\text { outro sem parar ... (CP I) }\end{array}$ \\
\hline Curió trola & $\begin{array}{l}\text { atributo dado ao curió que tem um tipo } \\
\text { de canto atrapalhado, misturado, com } \\
\text { diferentes sequências sonoras. }\end{array}$ & $\begin{array}{l}\text {... já tive curió trola ... era muito } \\
\text { cantador, mas esse canto não me } \\
\text { agrada ... é misturado ... acho feio } \\
\text { mesmo ... (CP VIII) }\end{array}$ \\
\hline
\end{tabular}

Fonte: Dados catalogados durante a pesquisa, 2017.

\subsubsection{Análise dos fraseologismos}

Consideramos apropriado para este trabalho discutir a definição de fraseologismo baseado em Mejri (1997). Esse autor considera que o referido fenômeno linguístico se materializa por meio de associações sintagmáticas recursivas em práticas de linguagem específicas de um campo do conhecimento.

Quando selecionamos as seis unidades fraseológicas, conforme quadro de número oito, tivemos por intento mostrar, justamente, essas associações sintagmáticas que circulam em um ambiente especifico do saber, a atividade dos passarinheiros na região do Caeté. Assim estamos em consonância com Mejri (1997).

De acordo com a pesquisa que realizamos, as fraseologias integram um discurso próprio, que encontra sua razão comunicativa para um grupo de pessoas que partilham de experiências, costumes, práticas e saberes: os passarinheiros. Deslocado das 
conversas dos passarinheiros, tais usos podem ser incompreensíveis e perdem importância comunicativa, daí a necessidade do registro e da análise desse fenômeno linguístico tão recorrente e repleto de importância para os passarinheiros.

Atentamos, ainda, para o que diz Gouadec (1994:173), segundo quem, as fraseologias são fórmulas que expressam um conteúdo próprio de um âmbito. E funcionam como cadeias de caracteres estereotipadas e frequentes, em determinado discurso, constituídas de elementos invariáveis e variáveis. Gouadec faz uma divisão das unidades fraseológicas: unidades com pivô terminológico e sem pivô terminológico ${ }^{17}$. Consideramos os fraseologismos com o termo "curió", unidades com pivô terminológico em que "curió", é a parte fixa, o núcleo do fraseologismo. Desse modo, nas construções linguísticas curió fogo crônico, curió preseiro, curió maracajá, curió preto, curió quente, curió trola, temos uma parte que é fixa: curió, portanto denominada pivô e que admite, nesses exemplos, seis variáveis.

\section{Considerações Finais}

Procuramos, na investigação que resultou neste artigo, realizar um estudo no âmbito do léxico, tendo a socioterminologia e a fraseologia, mais especificamente os fraseologismos com pivô terminológico, como suportes teórico e metodológico para mostrar e analisar aspectos imbricados nos usos linguísticos da atividade dos passarinheiros na região do Caeté, Pará.

Nossa pesquisa traz, para os estudos linguísticos, um aspecto interessante: o fato de trabalhar com linguagem de especialidade na dimensão sociocultural, prática acadêmica pouco explorada no âmbito dos estudos lexicais, pois, geralmente, o corpus elencado para a elaboração de uma pesquisa que trata das línguas de especialidade enquadra-se nos campos de conhecimentos já consagrados e reconhecidos no meio técnico e científico.

A análise socioterminológica dos termos simples nos permitiu observar o quanto os usos linguísticos são variáveis, ora mantendo-se no campo do léxico geral, ora restringindo-se ao léxico de especialidade. A apreciação dos fraseologismos com o

17 No léxico dos passarinheiros encontramos diversos exemplos de fraseologismos sem pivô terminológico, mas por um critério de recorde metodológico optamos por não contemplá-los em nossa análise. 
termo "curió" traz para este trabalho um resultado instigante e qualitativo na medida em que nos faz refletir sobre as possibilidades semânticas que um lexema simples comporta quanto se reveste em um sintagma com pivô terminológico, neste caso, para integrar o vocabulário de um grupo de pessoas que compartilha de práticas culturais e, por conseguinte, de uma linguagem muito peculiar.

É evidente que o estudo da socioterminologia e da fraseologia especializada também se relaciona à pesquisa sobre os discursos especializados, e o aprofudamento de seu estudo pode trazer importantes contribuições para as pesquisas lexicais. Finalmente, constatamos que prender pássaro é uma prática sociocultural transmitida de geração a geração e assimilada com vigor e discernimento pelos mais jovens. Há um movimento em torno da legalização da atividade dos passarinheiros, mas que vem sendo acompanhado com rigor pelos órgãos de controle ambiental. Contudo, não tivemos por objetivo levantar tal discussão neste trabalho, uma vez que nossa pesquisa se atém a aspectos direcionados aos usos linguísticos dos passarinheiros na região do Caeté, Pará. 


\section{REFERÊNCIAS}

ALVES, Elizabeth. Uma perspectiva léxico-funcional de cristalização e variação nos fraseologismos verbais. A linguagem de especialidade 'Economia/Negócios/Finanças. Brasília: UNB. Dissertação de mestrado, 2002.

BEVILACQUA, Cleci Regina. Fraseologia: perspectiva da língua comum e da língua especializada. Língua \& Literatura, 10-11, pp. 73-86, 2005. Disponível em http://www.revistas.fw.uri.br/index.php/revistalinguaeliteratura/article/view/40. Acessado em: 05 de jan. 2020.

BARROS, Lídia Almeida. Curso básico de Terminologia. São Paulo: EDUSP, 2004.

BORBUJO, Arturo. Terminología y socioterminología. IN Real, E., Jiménez, D., Pujante, D. y Cortijo, A. (eds.), Écrire, traduire et représenter la fête, Universitat de València, 2001.

BOULANGER, Jean-Claude. Convergências e divergências entre Lexicografia e Terminografia. In: LIMA, Marília dos Santos e RAMOS, Patrícia Chittoni (org.). Terminologia e ensino de segunda língua: Canadá e Brasil. Porto Alegre: UFRGS, 2001.

COSTA, Eduardo; PIRES, Geovana. As 12 cidades polos das regiões de Integração do estado do Pará. Disponível em: http://seplan.pa.gov.br/sites/default/files/PDF/loa/loa2016/13.anexo_x_regioes_de_inte gracao_e_municipios_do_estado_do_para.pdf. Acessado em: 07 de jan. 2020.

FAULSTICH, Enilde. A socioterminologia na comunicação científica e técnica. Cienc. Cult. [online]. 2006, vol.58, n.2, pp. 27-31. ISSN 2317-6660.

FAULSTICH, Enilde. Socioterminologia: mais que um método de pesquisa, uma disciplina. Ciência da Informação, v. 24, n. 3, 1995. 136. 
FAULSTICH, Enilde. Base metodológica para pesquisa em socioterminologia: termo e variação. Brasília: Centro Lexterm, 1995.

KOCK, Ingedore Grunfeld Villaça. O texto e a construção dos sentidos. São Paulo: Contexto, 1997.

GIL, Antonio Carlos. Métodos e técnicas de pesquisa social. 5.ed. São Paulo: Atlas, 1999.

ISO 1087(1990). Terminology - Vocabulary = Terminologie - Vocabulaire, Genève, Organisation internationale de normalisation (ISO/TC 37).

LAKATOS, Eva Maria; MARCONI, Eva Marina de Andrade. Fundamentos de metodologia científica. 5. Ed. São Paulo: Atlas 2003. Disponível em: https://docente.ifrn.edu.br/olivianeta/disciplinas/copy_of_historia-i/historia-ii/china-eindia. Acessado em: 03 de jan. 2020.

KRIEGER, Maria da Graça e FINATTO, Maria José Bocorny. Introdução à terminologia: teoria e prática. São Paulo: Contexto, 2004.

MARTINS, Vicente de Paula da Silva. Estratégias de compreensão de expressões idiomáticas por não nativos do português brasileiro. Tese (Doutorado) - Universidade Federal do Ceará, Departamento de Letras Vernáculas, Programa de Pós-graduação em Linguística, Fortaleza (CE), 2013.

MEJRI, S. Le figement lexical: descriptions linguistiques et structuration sémantique. Manouba: Publications de la Faculté des Lettres de la Manouba, 1997.

MONTEIRO-PLANTIN, Rosemeire Selma. Gastronomismos linguísticos: um olhar sobre Fraseologia e cultura. In ORTIZ, Alvarez Maria Luisa e UNTERNBAUMEN, Enrique Huelva. (Orgs.). Uma (re)visão da teoria e da pesquisa fraseológicas. São Paulo: Pontes, 2011. 
NOGUEIRA-NETO, Paulo. A criação de animais indígenas vertebrados. São Paulo. Edições Tecnapis, 1973.

OLIVEIRA, Luciana de Fátima. A importância dos Tupinambá na formação da vila de Bragança - Estado do Grão Pará: 1740-1760. In: XIII Encontro ANPUH-Rio. Anais (on-line). Rio de Janeiro. Disponível em: http://encontro2008.rj.anpuh.org/resources/content/anais/1212954877_ARQUIVO_AR TIGOparaoRIODEJANEIRO.pdf. Acesso em 05 de jan. 2020.

ORTIZ, ALVAREZ, ML. A fraseologia do meio ambiente: análise conceitual e terminológica. In: Anais da 60a Reunião anual da SBPC. Campinas, 2008.

SOUSA, Paulo Santiago de. O léxico dos passarinheiros na região do Caeté: um estudo socioterminológico. Universidade Federal do Pará. Dissertação de Mestrado em Linguagens e Saberes na Amazônia. Bragança, Pará, p. 17. 2018.

ROSA, Maria Virgínia de Figueirdedo Pereira Couto; ARNOLDI, Marlene Aparecida Gonzales Colombo. A Entrevista na pesquisa qualitativa: mecanismo para validação dos resultados. Belo Horizonte: Autêntica, 2006.

SICK, Helmut. Ornitologia brasileira. Rio de Janeiro, Nova Fronteira, 1997. 